\title{
Functional Performance of Ankles Between Male and Female Practitioners of Resistance Exercise
}

\author{
M. Braz ${ }^{1}$, A. Souto Maior ${ }^{2}$ \\ 1 Master in Rehabilitation Science at UNISUAM (Augusto Motta University Center), Rio de Janeiro, Brazil \\ 2 PhD in Exercise Physiology, Professor of the Master's and Doctorate Program in Rehabilitation Science at \\ UNISUAM (Augusto Motta University Center), Rio de Janeiro, Brazil
}

\section{CORRESPONDING AUTHOR:}

Alex Souto Maior

Augusto Motta University Center

(UNISUAM)

Postgraduate Program in Rehabilitation

Sciences

Praça das Nações 34, Bonsucesso

Rio de Janeiro, Brasil

E-mail: alex.bioengenharia@gmail.com

DOI:

10.32098/mltj.04.2021.13

LEVEL OF EVIDENCE: 1B

\begin{abstract}
SUMMARY
Background. Gender difference has shown that females exhibit a greater the ankle range of motion $(\mathrm{ROM})$ than males. On the other hand, few studies have examined the link between the ankles ROM, muscle strength and functional performance (FP) in the gender difference.

Objective. The purpose of this investigation was to compare the ankles ROM, ankle isometric muscle strength and ankle PFP between males and females practitioners of resistance exercise.

Methods. Males $(n=20)$ and females $(n=20)$ healthy were recruited. All participants underwent three tests to assess the ROM, muscle strength and FP of the ankles, respectively. ROM measurements were taken in both ankles with a digital goniometer. Ankle isometric muscle strength was measured using a load cell. Ankle FP was assessed with the Single Leg Hop Test (SLHT) in both limbs.

Results. Plantar flexion ROM was significantly greater in the females than males for both ankles $(\mathrm{p}<.01)$. No significant difference $(\mathrm{p}>.05)$ was found between the groups for ankle-dorsiflexion ROM. Isometric muscle strength during dorsiflexion was significantly lower in the females for both ankles $(\mathrm{p}<.01)$. SLHT showed demonstrating better FP in the males $(\mathrm{p}<.001)$. Isometric muscle strength during plantar flexion was significantly correlated with plantar flexion ROM in males $(r=0.52 ; \mathrm{p}<.02)$ and females $(\mathrm{r}=0.46 ; \mathrm{p}<.03)$.

Conclusions. This study showed the better ankles FP and greater isometric muscle strength during ankle-dorsiflexion and plantar flexion in males. On the other hand, plantar flexion ROM was greater in females.
\end{abstract}

\section{KEY WORDS}

Ankles; functional performance; range of motion; resistance training; sex differences.

\section{INTRODUCTION}

Resistance exercise (RE) is a systematic physical activity modality with the objective of increase muscle strength to overcome resistance $(1,2)$. Thus, RE have been suggested in sports guidelines aiming at improving physical conditioning and health (3). This physical activity modality is a combination of dynamic actions and static effort with the principle of increasing muscle strength and power from multiple variables, such as: exercise order, rest interval between sets, exercise mode, training frequency, movement velocity, training volume, repetitions per set, number of sets, type of muscle action, and the load intensity that can all be manipu- lated to meet the training goals and individual differences in training needs $(1,2,4)$. But, interestingly, in regard to range of motion (ROM), muscle strength and functional performance of ankles there are a limited number of studies that have assessed gender difference (males $v s$ females) of practitioners of RE.

The ankle joint complex is formed by the dome of the talus fitting into a mortise formed by the tibia and the fibula where this joint produces movements of dorsiflexion and plantar flexion of the foot. Dorsiflexion is the movement at the ankle joint where the toes are brought closer to the shin, curling upwards and decreasing the angle between 
the dorsum of the foot and the leg $(5,6)$. On the other hand, plantar flexion describes the extension of the ankle so that the foot points down and away from the leg (7). A normal ankle moves from approximately $20^{\circ}$ dorsiflexion to $50^{\circ}$ plantar flexion in the sagittal plane and total range of motion in the frontal plane is approximately $35^{\circ}\left(23^{\circ}\right.$ inversion; $12^{\circ}$ eversion) $(5,8,9)$. Adequate ankle mobility allows the lower limb to interact with the ground being a fundamental requirement for walking, body stability and activities of daily living. On the other hand, a limited ankle $\mathrm{ROM}$ is associated with a greater dynamic knee valgus and medial knee displacement, as well as a reduced activation of the quadriceps and increased activation of the soleus $(5,8,9)$.

Gender difference has shown that females exhibit a greater ankle ROM than males. Possibly, because muscle stiffness is lower in females, since contribute with higher tolerance to muscle stretch being responsible for increased ROM (10). Besides, the females show high geometrical parameters of plantar flexor's muscle-tendon complex active parts of the series elastic component (11). Another important factor observed in the scientific literature was the greater ROM at the talocrural and subtalar joints in females (12). Thus, ROM of the ankles plantar flexion for females is greater than males; but ROM of ankle-dorsiflexion no significant gender difference (13).

On the other hand, few studies have examined the link between the ankles ROM, muscle strength and functional performance in the gender difference. Accordingly, the aim of this study was to compare the ankle ROM, ankle isometric muscle strength and ankle functional performance between males and females practitioners of RE.

\section{METHODS}

\section{Study design}

This is a randomized comparative study. The sample size was determined by including all participants that complied with the eligibility criteria. All participants (male and female) were practitioners of resistance exercise and underwent three tests to assess ROM, strength, and functionality. All tests were performed in a single assessment session in the following order: anthropometric measurements; ankle range of motion (dorsiflexion and plantar flexion); ankle muscle strength; and ankle functional performance testing. All assessment were taken in a temperature-controlled environment (temperature $21{ }^{\circ} \mathrm{C}, 65 \%$ relative humidity) by a Hygro-Thermometer with Humidity Alert (Extech Instruments, Massachusetts, EUA). All assessments occurred between 2:00 and 4:00 P.M.

\section{Participants}

Forty participants were recruited and separated into two groups: male $(33.5 \pm 7.8$ years; $176.1 \pm 7.6 \mathrm{~cm} ; 79.6 \pm 7.8$ $\left.\mathrm{kg} ; 22.5 \pm 2.8 \mathrm{~kg} / \mathrm{m}^{2}, \mathrm{n}=20\right)$ and female $(29.5 \pm 7.1$ years, $\left.164.3 \pm 8.7 \mathrm{~cm}, 67.1 \pm 8.9 \mathrm{Kg} ; 20.5 \pm 2.5 \mathrm{~kg} / \mathrm{m}^{2}, \mathrm{n}=20\right)$. All subjects regularly practiced resistance exercise $5.2 \pm 0.4$ days week $^{-1}$ and low aerobic training of $1.3 \pm 0.6$-day week ${ }^{-1}$ with a total volume of $252.7 \pm 8.3$ minutes per week. Subjects with at least one year of resistance exercise experience were included to participate in the current study. Exclusion criteria included: 1) use of anabolic steroids, drugs, or medication with potential impact in physical performance (self-reported); 2) presence of musculoskeletal injury in the past 6 months and 3) previous hip, knee, and/or ankle surgery. All participants performed a routine of RE that engaged the whole body with resistance bands, free-weights, and medicine balls. All participants completed the Physical Activity Readiness Questionnaire (PAR-Q). This study was approved by the Ethical Committee for Human Experiments of the Augusto Motta University Center, Rio de Janeiro, Brazil (CAAE: 32033420.1.0000.5235). The present study was conducted at the Rehabilitation Science Center, Augusto Motta University Center, Rio de Janeiro, Brazil meeting the ethical standards of the jornal (14). The study was performed in accordance with ethical standards in sport and exercise science research. All participants were informed of the experimental procedures and gave written informed consent prior to participation. No clinical problems occurred during the study.

\section{Anthropometric measurements}

Body composition was measured following an 8-h overnight fast by bioelectrical impedance analysis using a device with built-in hand and foot electrodes (BIO 720, Avanutri, Rio de Janeiro, Brasil). The participants wore their normal indoor clothing and were instructed to stand barefoot in an upright position with both feet on separate electrodes on the device's surface and with their arms abducted and both hands gripping two separate electrodes on each handle of the device. All biometric measurements were carried out in an air-conditioned room $\left(21^{\circ} \mathrm{C}\right)$. No clinical problems occurred during the study.

\section{Ankle dorsiflexion and plantar flexion range of motion}

Measurements were taken in both ankles with a digital goniometer (Global Medical Devices; Maharashtra, India). Ankle-dorsiflexion and plantar flexion ROM were 
measured with the subjects lying supine with an extended knee on a standard treatment table. This position was selected because both hip and knee joints are extended simultaneously, simulating the stance phase of gait just before heel-off (15). During assessments, all subjects wore shorts to provide adequate exposure to the ankle-foot-leg complex and were instructed to actively do a dorsiflexion and plantar flexion of the ankle joint (i.e., as far as comfortable without pain).

The rotational axis of the goniometer was placed just distally to the lateral malleolus, and the goniometer arms were aligned with the head of the fibula and parallel to the fifth metatarsal, respectively. The convention was followed of neutral position being $0^{\circ}$ and ankle motion being the number of degrees of angular movement from that position in either a dorsal or plantar direction. Measurements were recorded in degrees, and the mean score of three measurements was computed. This testing method has shown intra-rater reliability measures greater than 0.93 for the assessment of the active ankles ROM.

\section{Ankle Isometric Muscle Strength Testing}

Ankle isometric muscle strength was measured using a commercially available load cells (E-lastic, E-sports Soluções Esportivas, Brasilia, Brazil). During the assessments, the left and right forefoot were individually secured by bands and fixed in the load cells. Participants performed three times (dorsiflexion and plantar flexion) for both ankles and the highest value obtained from the three trials was used for statistical analysis (figure 1). All assessments were performed with the subjects lying supine with an extended knee on a standard treatment table. Force values were registered during 5 seconds of isometric contraction and rest interval of 60 secs between the trials. Isometric force data of load cell were simultaneously transferred via Bluetooth to a mobile cellphone (sample rate $=10 \mathrm{~Hz}$ ). Verbal encouragement was always provided, and no subjects were excluded through injury during the experimental procedure. This testing method has shown intra-rater reliability measures greater than 0.94 .

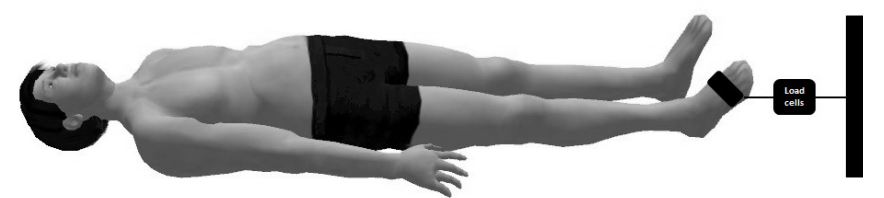

Figure 1. Ankle isometric muscle strength testing.

\section{Ankle Functional Performance Testing}

Ankle functional performance was assessed with the single leg hop test performed bilaterally (right and left).
Subjects, with footwear, positioned themselves single leg $30 \mathrm{~cm}$ behind of the first photocell beam (Brower Timing System, Salt Lake City, 174 UT, USA; accuracy of 0.01 sec) (figure 2). For the time record, subjects covered as fast as possible a 6-m distance that was timed by the second photocell beam. The test was repeated three times for both legs and a mean score of the three trials was then calculated. The subjects rested for 30 secs between the trials. Verbal encouragement was always provided, and no subjects were excluded through injury during the experimental procedure. This test it was valid when it exhibits reliability that is higher than 0.90 . Prior to functional performance testing, participants conducted a 10-min mobility and stability exercise.

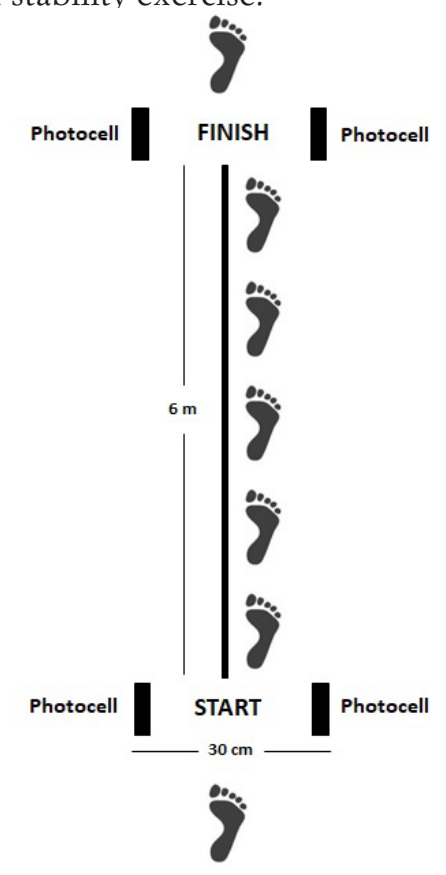

Figure 2. Schematic diagram of the single-leg hops for time test.

\section{Statistical analysis}

All data are presented as mean \pm standard deviation. Statistical analysis was initially performed using the ShapiroWilk normality tests and the homoscedasticity test (Bartlett criterion). To test the reproducibility between the tests, the intraclass correlation coefficient (ICC) was used. Two-way analysis of variance (ANOVA) was used to test for main and interaction effects of the group (males $v$ s females) and timing of measurement for each outcome variable independently (right $v$ s left) and the post hoc Bonferroni was used to possibility a statistically significant. Correlations between variables were assessed using Pearson correlation coefficients and their corresponding $95 \%$ confidence intervals. The level of statistical significance was set at an alpha 
level of $\mathrm{P}<0.05$ using GraphPad Prism ${ }^{\circledR}$ software (Prism 6.0, San Diego, CA, USA).

\section{RESULTS}

The two-way ANOVA yielded main effects for group $\left(\mathrm{F}_{(1,37)}\right.$ $=10.70, p<.002)$, such that Bonferroni post- hoc showed significant differences in plantar flexion ROM between males vs females group for both ankles (table I). No significant difference $(\mathrm{p}>$.05) was found between the groups (male $v$ f female) to dorsiflexion ROM. Absolute isometric muscle strength during dorsiflexion $\left(\mathrm{F}_{(1,37)}=9.06, \mathrm{p}<.004\right)$ and plantar flexion $\left(\mathrm{F}_{(1,37)}=11.46, \mathrm{p}<.001\right)$ showed main effects for groups demonstrating that it was significant- ly lower in the females when compared to males for both ankles $(\mathrm{p}<.01)$ (table I).

Table II compares the ankle functional performance during single leg hop test between males $v s$ females. Single leg hop test showed main effects for groups (Second: $\mathrm{F}_{(1,37)}=69.77$, p $<.0001 ; \mathrm{m} / \mathrm{s}: \mathrm{F}_{(1,37)}=74.58, \mathrm{p}<.0001 ; \mathrm{km} / \mathrm{h}: \mathrm{F}_{(1,37)}^{(1,3)}=74.50, \mathrm{p}$ $<.0001)$ demonstrating better functional performance in the males when compared to females for both ankles $(\mathrm{p}<.001)$ (table II). In addition, number of jumps ratio also showed main effects for groups $\left(F_{(1,37)}=59.00, \mathrm{p}<.0001\right)$, such that Bonferroni post- hoc showed significant differences $(\mathrm{p}<.001)$ between males $v$ s females group for both ankles (table II).

Table III showed no correlation significant between single leg hop test and ankle range of motion. On the other hand, Pear-

Table I. Performance of ankle range of motion, absolute and relative isometric muscle strength between males vs females practitioners of resistance exercise $(n=40)$.

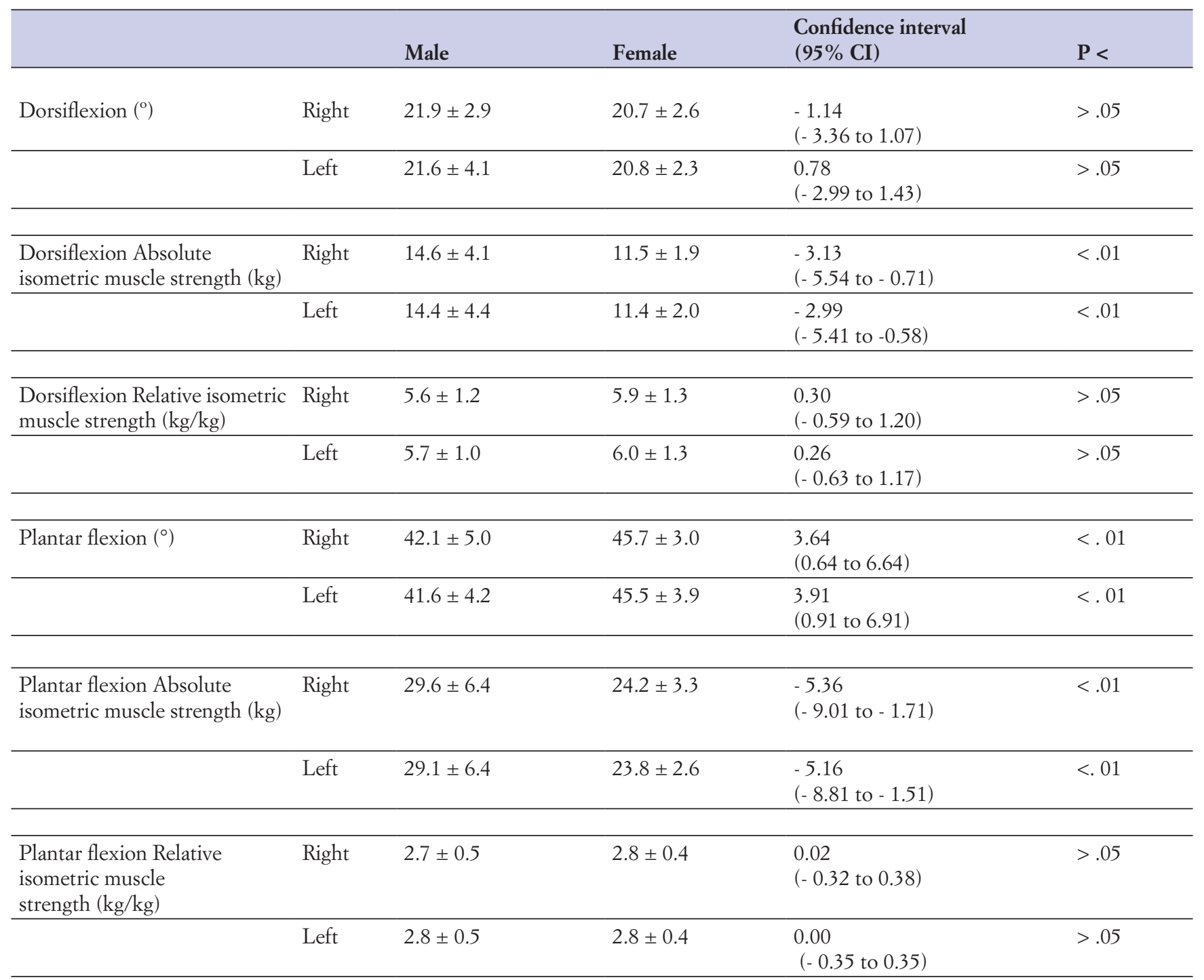


Table II. Performance during single leg hop test between male vs female practitioners of resistance exercise ( $\mathrm{n}=40$ ).

\begin{tabular}{|c|c|c|c|c|c|}
\hline & & Male & Female & $\begin{array}{l}\text { Confidence interval } \\
(95 \% \text { CI })\end{array}$ & $\mathbf{P}<$ \\
\hline \multirow[t]{2}{*}{$\begin{array}{l}\text { Single Leg Hop } \\
\text { test (sec.) }\end{array}$} & Right & $1.8 \pm 0.2$ & $2.6 \pm 0.4$ & $\begin{array}{l}0.78 \\
(0.54 \text { to } 1.02)\end{array}$ & $<.001$ \\
\hline & Left & $1.9 \pm 0.2$ & $2.7 \pm 0.3$ & $\begin{array}{l}0.77 \\
(0.54 \text { to } 1.01)\end{array}$ & $<.001$ \\
\hline $\begin{array}{l}\text { Single Leg Hop } \\
\text { test }(\mathrm{m} / \mathrm{s})\end{array}$ & Left & $3.1 \pm 0.3$ & $2.2 \pm 0.3$ & $\begin{array}{l}-0.89 \\
(-1.15 \text { to }-0.63)\end{array}$ & $<.001$ \\
\hline $\begin{array}{l}\text { Single Leg Hop } \\
\text { test }(\mathrm{km} / \mathrm{h})\end{array}$ & Right & $11.6 \pm 1.3$ & $8.2 \pm 1.3$ & $\begin{array}{l}-3.34 \\
(-4.28 \text { to }-2.40)\end{array}$ & $<.001$ \\
\hline \multirow[t]{2}{*}{ Number of jumps } & Right & $3.1 \pm 0.3$ & $4.2 \pm 0.4$ & $\begin{array}{l}1.09 \\
(0.77 \text { to } 1.41) \\
\end{array}$ & $<.001$ \\
\hline & Left & $3.2 \pm 0.4$ & $4.1 \pm 0.4$ & $\begin{array}{l}0.93 \\
(0.62 \text { to } 1.25)\end{array}$ & $<.001$ \\
\hline
\end{tabular}

Table III. Scatterplots displaying the correlation analysis (Pearson's coefficient) between performance during single leg hop test (second) and ankle range of motion $\left(^{\circ}\right)$ in male and female practitioners of resistance exercise $(n=40)$.

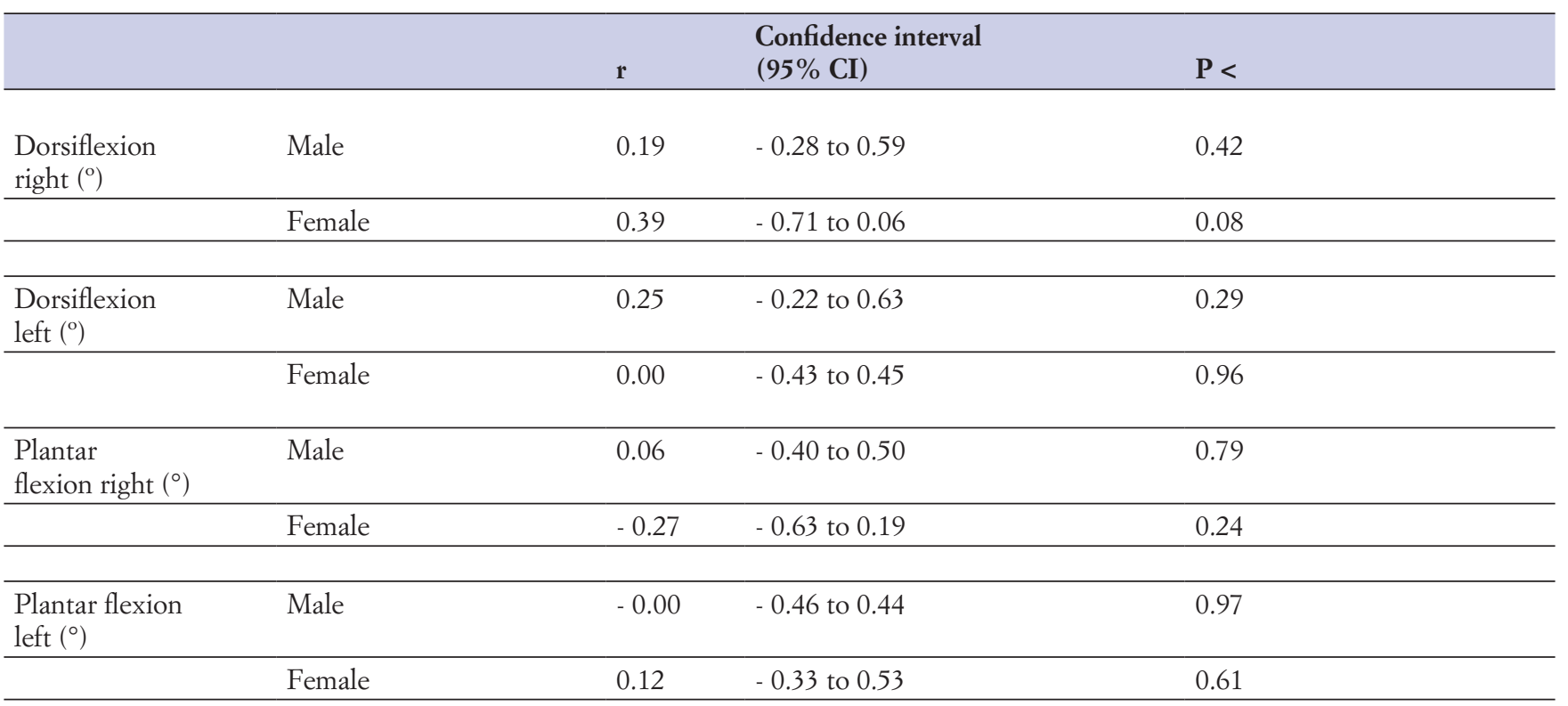

son's analysis showed that absolute isometric muscle strength during plantar flexion was significantly correlated with plantar flexion range of motion in males $(\mathrm{r}=0.52 ; \mathrm{p}<.02)$ and female $(r=0.46 ; \mathrm{p}<.03)$ for the right ankle (table IV).

Pearson's analysis also illustrated that performance in the single leg hop test was negatively correlated with absolute isometric muscle strength during dorsiflexion in female for both ankles (Right: $\mathrm{r}=-0.54$; $\mathrm{p}<.01$; left: $\mathrm{r}=-0.76$; $\mathrm{p}$ $<$.0001) (table V). Negative correlation also was observed between performance during single leg hop test and absolute isometric muscle strength during plantar flexion in female only for the left ankle $(\mathrm{r}=-0.44 ; \mathrm{p}<.04)$ (table V). 
Table IV. Scatterplots displaying the correlation analysis (Pearson's coefficient) between absolute ankle isometric muscle strength $(\mathrm{kg})$ and ankle range of motion $\left(^{\circ}\right)$ in male and female practitioners of resistance exercise $(n=40)$.

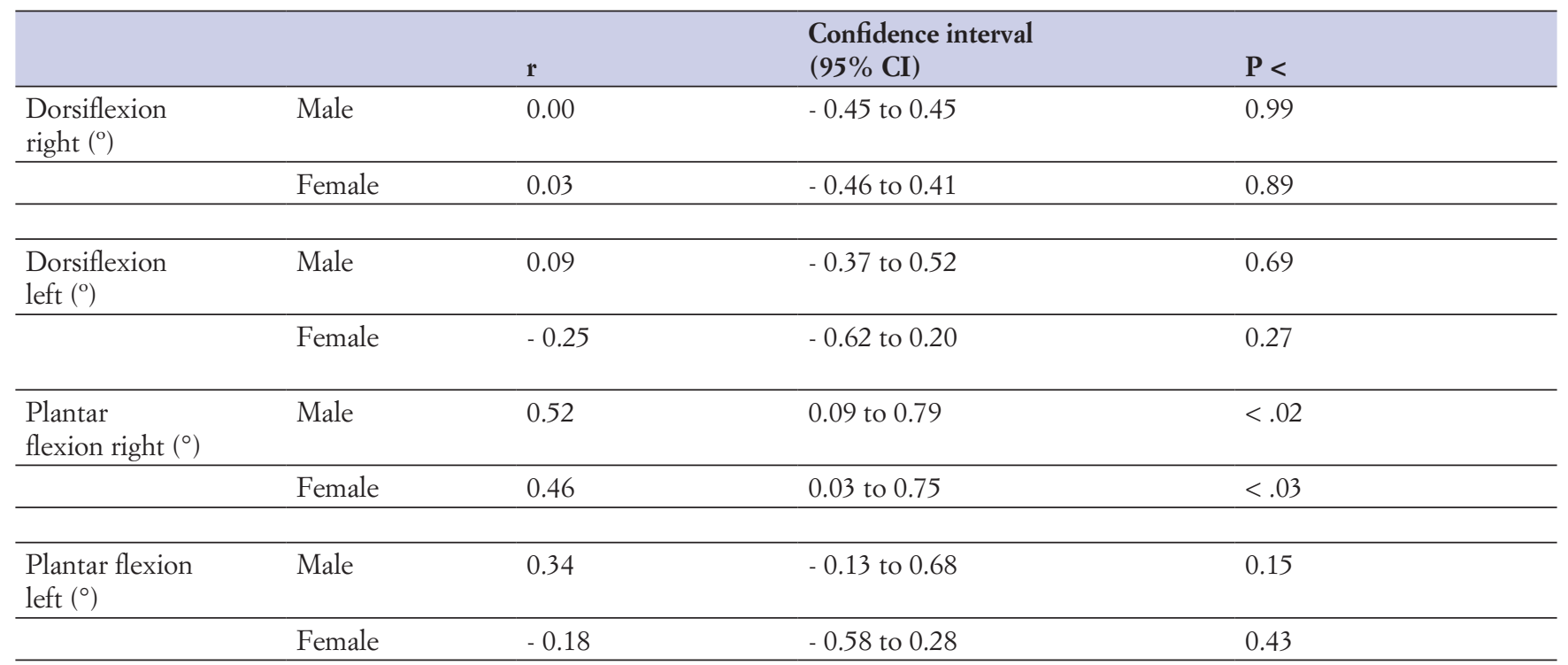

Table V. Scatterplots displaying the correlation analysis (Pearson's coefficient) between performance during single leg hop test (second) and absolute ankle isometric muscle strength $(\mathrm{kg})$ in male and female practitioners of resistance exercise $(\mathrm{n}=40)$.

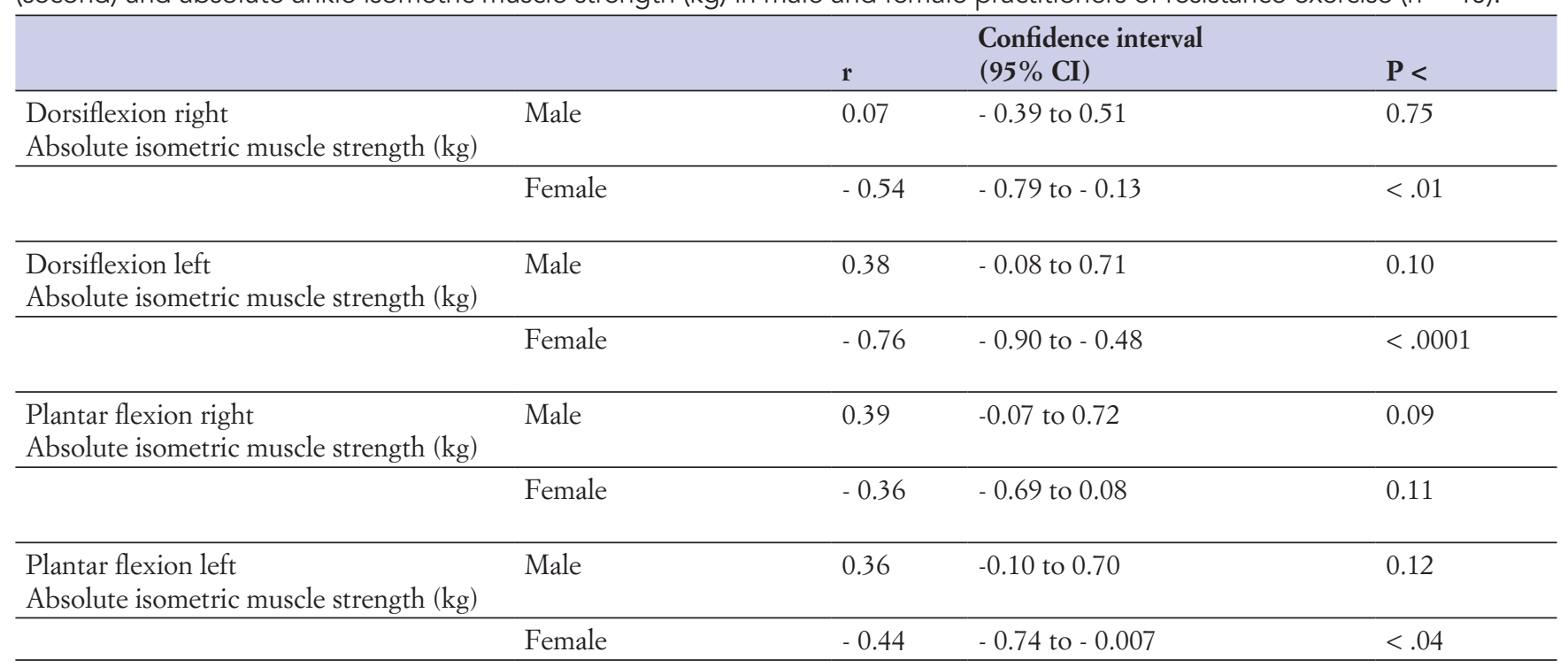

\section{DISCUSSION}

The present study showed that male showed greater absolute isometric muscle strength during dorsiflexion and plantar flexion. However, female showed greater plantar flexion ROM. On the other hand, was observed a significant correlation between absolute isometric muscle strength during plantar flexion and plantar flexion ROM in right ankle to both groups. But the main findings showed negative correlation between functional performance and absolute isomet- ric muscle strength during dorsiflexion in female for both ankles. In addition, females also showed negative correlation between functional performance and absolute isometric muscle strength during plantar flexion of the left ankle. Decreased strength of the ankle musculature decreases the ability to stabilize the lower extremity, resulting in a faulty alignment of the lower extremity (such as adduction and rotation of the hip and knee valgus) $(7,8)$. Specifical- 
ly, on the isometric muscle strength during dorsiflexion, our results showed that males had greater production of isometric strength than females $(21.2 \%$ and $20.8 \%$ in the right and left ankles, respectively). Other studies observed a gender difference of the isometric muscle strength during dorsiflexion between $28 \%$ and $39 \%(16,17)$. However, the studies did not use trained subjects $(16,17)$. It seems that the main factor for the gender difference in isometric dorsiflexion contraction is related to muscle cross-sectional area (CSA) of the tibials anterior (i.e., type II muscle fiber diameters in males is $20 \%$ larger than females) $(18,19)$. In addition, the deformation of the surrounding fascicles and retinaculum bands causes the tibials anterior distal tendon to shift away from the axis of rotation when going from rest to maximum muscle tension (20).

Plantar flexion describes the extension of the ankle so that the foot points down and away from the leg $(7,21)$. Thus, ankle plantar flexors are important muscles to control for the mechanical work during squat exercise while also to strengthen the posterior-lateral muscles of the leg $(7,21)$. Our results reported that males had greater production of isometric strength than females during plantar flexion $(18.2 \%$ and $18 \%$ in the right and left ankles, respectively). Some studies have shown that this gender difference in isometric strength muscle can be related to larger muscle physiological cross-sectional area (CSA) in males (CSA of type II fibers, fascicule length, and fascicule angles) being a factor that can contribute to greater isometric muscle strength $(11,22,23)$. In addition, males have a larger Achilles tendon CSA and series elastic component that likely related to increased force generation capacity in the muscle fibers $(11,22,23)$. On the other hand, our results showed greater ROM during plantar flexion in females when compared to males $(7.8 \%$ and $8.5 \%$ in the right and left ankles, respectively). These results may be related a higher stiffness of the series elastic component and tolerance to muscle stretch (muscle stiffness of plantar flexors) in males $(10,11,13)$.

The functional performance tests require agility to better represent functional movements and may be more difficult to perform with decreased strength and power of the ankle muscles $(7,24,25)$. The dorsiflexors are eccentrically contracting to control the concentrically contracted plantar flexors to prepare the foot for push-off during functional performance tests (Single Leg Hop) $(7,23,26)$. Thus, our results indicate that males showed greater power muscle during functional performance tests. In general, it seems that the morphological difference between genders is related to the better functional performance possibly associated with greater strength and power of the ankle muscles in males $(10,13,18,19)$.
Although our results showed a correlation between absolute ankle isometric muscle strength and plantar flexion ROM. A significant correlation was observed only in the right ankle for males and females. These results may be related to the fact that the dominant leg of the study participants was the right leg and contribute with greater pushing force that leads to more ROM at ankle plantar flexion required for the lower limb to propel the body forward towards toe-off (8). On the other hand, we observed a negative correlation between performance during the single leg hop test and the absolute ankle isometric muscle strength in females. This result makes us hypothesize the participation of other intrinsic factors (i.e., balance; coordination; action of the tibials anterior and triceps surae muscles) to improve functional performance since we also did not observe a significant correlation between performance during single leg hop test and ankle $\operatorname{ROM}(11,13,24)$. The limitations of the study include the absence of measures of physiological parameters of physical exertion, which would be interesting; this, yet, does not limit the answer to the study question. In addition, longitudinal studies are needed to define a cause-and-effect relationship between gender difference, resistance training model and ankle functional performance.

\section{CONCLUSIONS}

This study showed better ankle functional performance and greater absolute isometric muscle strength during ankle dorsiflexion and plantar flexion in males. On the other hand, plantar flexion ROM was greater in females. However, both genderes showed a positive correlation between absolute ankle isometric muscle strength and plantar flexion ROM. These data contribute to the qualitative and quantitative understanding of gender differences in normal ankle function and may be useful to better understand and treat ankle joint pathologies in a gender-specific manner.

\section{ACKNOWLEDGMENTS}

The investigators would like to thank the 40 healthy male and female that participated in the study. The study was supported by the Coordenação de Aperfeiçoamento de Pessoal de Nível Superior, Brazil (CAPES), Finance Code 001.

\section{CONFLICT OF INTERESTS}

The author declare thet they have no conflict of interests. 


\section{REFERENCES}

1. Marocolo M, Marocolo IC, Cunha FSB, Mota GR, Maior AS. Influence of percentage of $1 \mathrm{RM}$ strength test on repetition performance during resistance exercise of upper and lower limbs. Arch Med Deporte 2016;33(6):387-92.

2. Baz-Valle E, Schoenfeld BJ, Torres-Unda J, Santos-Concejero $\mathrm{J}$, Balsalobre-Fernández C. The effects of exercise variation in muscle thickness, maximal strength and motivation in resistance trained men. PLoS One 2019;14(12):e0226989.

3. American College of Sports Medicine. American College of Sports Medicine position stand. Progression models in resistance training for healthy adults. Med Sci Sports Exerc 2009;41(3):687-708.

4. McCartney N. Acute responses to resistance training and safety. Med Sci Sports Exerc 1999;31(1):31-7.

5. Lima YP, Ferreira VMLM, Lima POP, Bezerra MA, de Oliveira RR, Almeida GPL. The association of ankle dorsiflexion and dynamic knee valgus: A systematic review and meta- analysis. Phys Ther Sport 2018;29:61-9.

6. Lazarou L, Kofotolis N, Pafis G, Kellis E. Effects of two proprioceptive training programs on ankle range of motion, pain, functional and balance performance in individuals with ankle sprain. J Back Musculoskelet Rehabil 2018;31(3):437-46.

7. Maior AS, Lobo E, Braz M, Campos Jr, JC, Leporace G. Comparison of ankle range of motion and functional performance between practitioners of resistance exercise with freeweight vs. Machine. MOJ Sports Med 2020;4(3):81'5.

8. Brockett CL, Chapman GJ. Biomechanics of the ankle. Orthop Trauma 2016;30(3):232-38.

9. Kaufman KR, Brodine SK, Shaffer RA, Johnson CW, Cullison TR. The effect of footstructure and range of motion on musculoskeletal overuse injuries. Am J Sports Med 1999;27(5):585-93.

10. Miyamoto N, Hirata K, Miyamoto-Mikami E, Yasuda O, Kanehisa $\mathrm{H}$. Associations of passive muscle stiffness, muscle stretch tolerance, and muscle slack angle with range of motion: individual and gender differences. Sci Rep 2018;8:8274.

11. Fouré A, Cornu C, McNair PJ, Nordez A. Gender differences in both active and passive parts of the plantar flexors series elastic component stiffness and geometrical parameters of the muscle-tendon complex. J Orthop Res 2012;30(5):707-12.

12. Fukano M, Fukubayashi T, Banks SA. Gender differences in three-dimensional talocrural and subtalar joint kinematics during stance phase in healthy young adults. Hum Mov Sci 2018;61(4):117-25.

13. Cho KH, Jeon Y, Lee H. Range of Motion of the Ankle According to Pushing Force, Gender and Knee Position. Ann Rehabil Med 2016;40(2):271-78.

14. Padulo J, Oliva F, Frizziero A, Maffulli N. Muscles, Ligaments and Tendons Journal - Basic principles and recommendations in clinical and field Science Research: 2018 update. Muscles Ligaments Tendons J 2018;8(3):305-7.

15. Youdas J W, McLean T J, Krause D A, Hollman JH. Changes in active ankle dorsiflexion range of motion after acute inversion ankle sprain. J Sport Rehabil 2009;18(3): 358-74.

16. Patten C, Kamen G. Adaptations in motor unit discharge activity with force control training in young and older adults. Eur J Appl Physiol 2000;83(2-3):128-43.

17. Kent-Braun JA, Ng AV. Specific strength and voluntary muscle activation in young and elderly women and men. J Appl Physiol 1999;87(1):22-9.

18. Holmback AM, Porter MM, Downham D, Andersen JL, Lexall J. Structure and function of the ankle dorsiflexor muscles in young and moderately active men and women. J Appl Physiol 2003;95(6):2416-424.

19. Jaworowski $\AA$, Porter MM, Holmback AM, Downham D, Lexall J. Enzyme activities in the tibialis anterior muscle of young moderately active men and women: relationship with body composition, muscle cross-sectional area and fiber type composition. Acta Physiol Scand 2002;176(3):215-25.

20. Maganaris CN, Baltzopoulos V, Sargeant AJ. Changes in the tibialis anterior tendon moment arm from rest to maximum isometric dorsiflexion: in vivo observations in man. Clin Biomech 1999;14(9):661-66.

21. Michael JM, Golshani A, Gargac S, Goswami T. Biomechanics of the ankle joint and clinical outcomes of total ankle replacement. J Mech Behav Biomed Mater 2008;1(4):276e94.

22. Westh E, Kongsgaard M, Bojsen-Moller J. Effect of habitual exercise on the structural and mechanical properties of human tendon, in vivo, in men and women. Scand J Med Sci Sports 2008;18(1):23-30.

23. Blackburn JT, Padua DA, Guskiewicz KM. Muscle stiffness and spinal stretch reflex sensitivity in the triceps surae. J Athl Train 2008;43(1):29-36.

24. Shiravi Z, Shadmehr A, Moghadam ST, Moghadam BA. Comparison of dynamic postural stability scores between athletes with and without chronic ankle instability during lateral jump landing. Muscles Ligaments Tendons J 2017;7(1):119-24.

25. Bergamin M, Gobbo S, Bullo V, Vendramin B, Duregon F, Frizziero A, Di Blasio A, Cugusi L, Zaccaria M, Ermolao A. Reliability of a device for the knee and ankle isometric and isokinetic strength testing in older adults. Muscles Ligaments Tendons J 2017;7(2):323-30.

26. Newton RU, Gerber A, Nimphius S, Shim KJ, Doan BK, Robertson M. Determination of functional strength imbalance of the lower extremities. J Strength Con Res 2006;20(4):971-77. 